\title{
Study On The Significance of Old-Age Instustry In Shaanxi Province
}

\author{
Xiao-Jing DONG \\ Xijing University, Xi'an, Shaanxi, China \\ E-mail:664186437@qq.com
}

\begin{abstract}
The number of old people in Shaanxi province, has kept rising. At the same time, the structure of population has broken the old structure. The province steps into the era of aging. Its economy market has been adjusted with the population change of Shaanxi Province. Now, we face the most important two problems-------how to raise the old age and how to solve lots of college graduates and unemployed people to obtain employment. The paper deeply researched the willing and situation of old people in Shaanxi Province and studied the related literature review, put forward the thought of developing the company pension industry. It is the win-win solution to let old people happy and make many jobs now.
\end{abstract}

Keywords-old-age instustry, industrial structure adjustment, dependency ratio of population, supply and demand

\section{INTRODUCTION}

Old people is defined, whose age is over the age of 60 , in China. Now, China is not only NO.1 in population size, but also in the number of old people. China could grow old before it grows wealthy, given the one-child policy and rising longevity. Population aging is the dynamic of the corresponding increase in the proportion of old people, with the decrease in the number of young people in the total population. The international community usually accounts for $10 \%$ of the population over the age of 60 . We must face the most important two problems--how to raise the old age and how to help lots of college graduates and unemployed people to obtain employment.

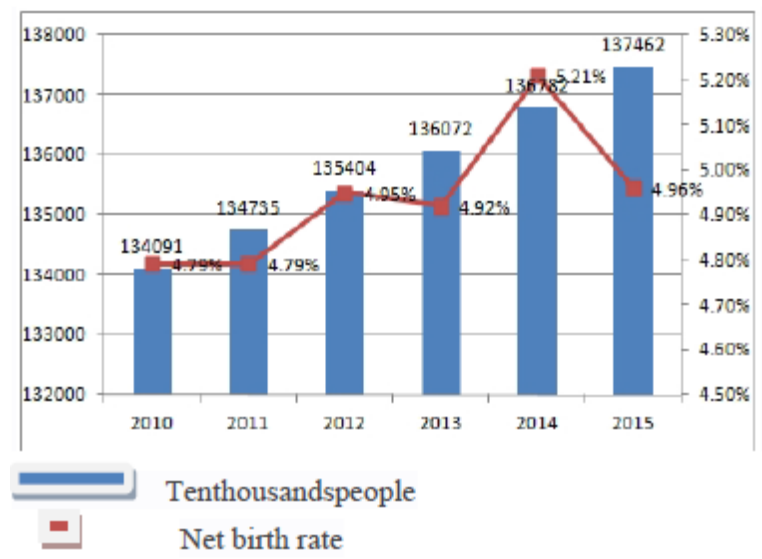

Figure 1. Chinese total population and natural growth rate in 2010-2015
Shaanxi Province is facing these same problems. Can we resolve them? The paper deeply investigated graduates and visited old people and adults, found the win-win answer.

\section{ANALYZE THE PRESENT SITUATION FOR THE OLD PEOPLE IN SHAANXI PROVINCE}

On July 7, 2017, a press conference was opened. The development of the old-age service industry announced, the total number of elderly people (over 60 years old) was 6.13 million by 2016 , accounting for $16 \%$ of the total population in Shaanxi Province. The aged population is growing at a rate of 3 per cent a year and will be expected to reach 6.9 million by 2020.The number of old people is keeping fast increase, as follows:

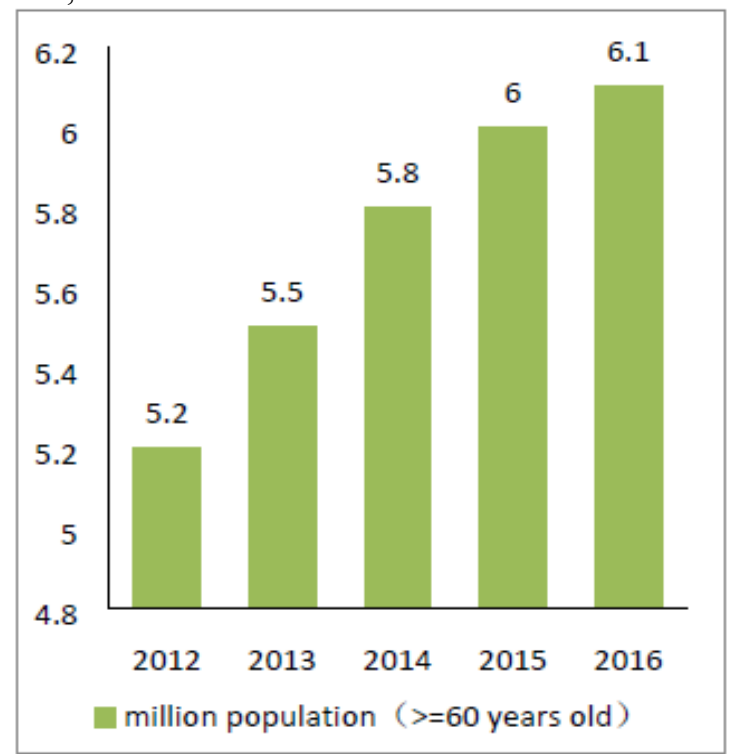

Figure 2. Old-Aged Composition in Shaanxi

In demography research Dependency Ratio of Population (DRP) refers to the ratio of the population A (aged under 15 or over 64) to the general population B (aged from15 to 64), expressed as a percentage. Its formula is namely $\mathrm{A} / \mathrm{B}$. It instructs that per 100 working-age people roughly afford the people whose ages are outside of working-age. In Shaanxi Province, it is displayed by chart3. 


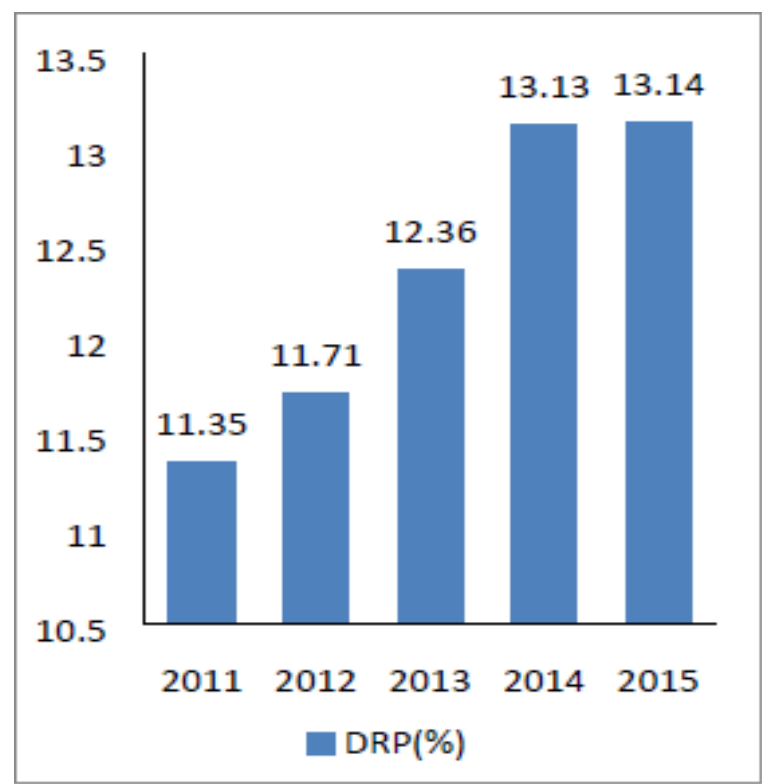

Figure 3. 2011-2015 DPR in Shaanxi Province

These data's can tell us the burden of adults in Shaanxi Province. At present, there is a common family structure '4-2-1', an inverted pyramid shape. A couple has only a kid. The policy had been kept for over thirty years, so that it has happened that there are huge changes in family pension mode. Although the family planning policy was adjusted, which is 'the second child is permitted' since 2016, it could alleviate the pressure of the endowment effect at least 18 years to emerge. In a word, the value of DRP is larger and larger by year, which means that the burden of labor is more severe. Every family faces the huge burden of raising old people and children.

\section{Research The Number Of College GRADUATES AND UNEMPLOYED PEOPLE}

At present, Chinese expansion policy in college students causes that the number of college graduates has soared. In 2011, the number of college graduates was 285 thousands, but in 2016, the number kept increasing. Promulgated by Chinese academy of social sciences in 2013 fresh graduate's employment survey showed that graduates from the perspective of the urban and rural sources of rural families become the ordinary undergraduate course colleges and universities graduate obtain employment were the most difficult group, the unemployment rate was as high as $30.5 \%$.

With economic slowdown, our country faces industry adjustment. Our province faces the same era of industry adjustment. The government and social company's create job chance to decrease. The existing unemployed and the coming college graduates increase society employment pressure. The reasons lead directly to unemployment after their graduation. The total number of permanent residents in the province reached 3812.62 million in 2016, in that our unemployed people attained 114.38 million.

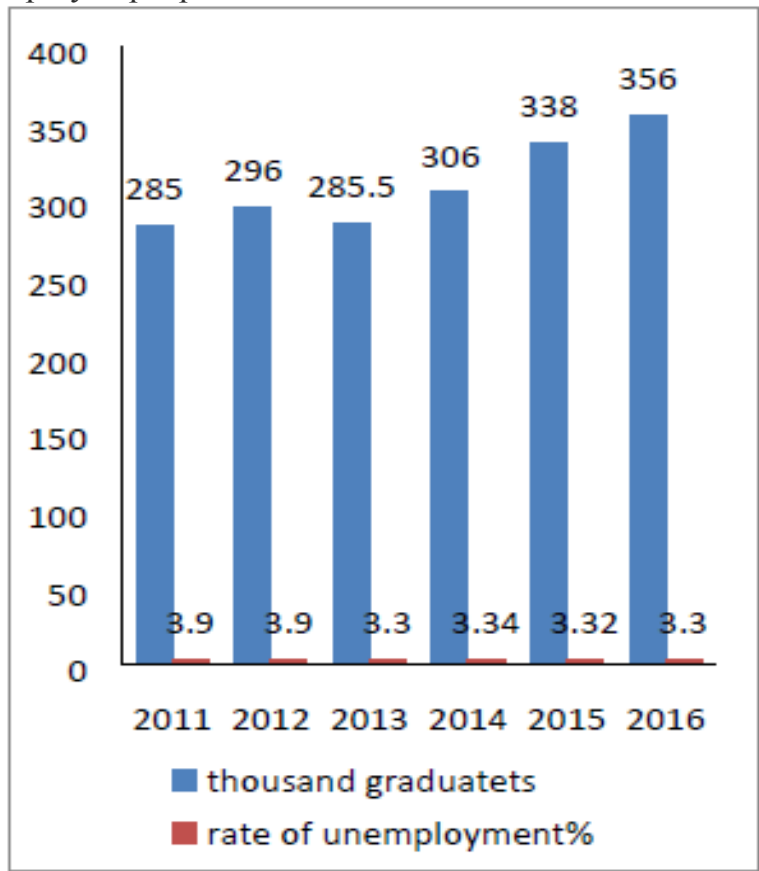

Figure 4. 2011-2016 the number of college graduates in Shaanxi Province

\section{ANALYZE THE WAY OF THESE PROBLEMS}

The gender imbalance, the shortage of migrant workers and the aging of the population are the current status of the society. However, these unprecedented problems have brought new challenges to the family planning policy. In order to balance the population proportion and solve social problems such as population aging, the country has formulated a new family planning policy--'couple could have two children'. But the behalf and goodness will be showed after 18 years.

At present, we face two important problems. On the one hand, old people could not get enough good help, on the other hand, many people are unemployed.

DPR is too high. It shows that adults must have enough money to raise their family members, including their fathers, matters, fathers in law, and mothers in law, children and them. They must go out to work so that they have no enough time to tend their parents and children. Society job competition is intense, and speed up the pace of life in individuals, families facing huge pension pressure. But in society, there are a lot of jobless people who lose jobs or graduates without employment. Not only Family adults but also jobless people have huge tension. Some of all are too busy to have enough time to do everything, but some of all have enough time and do nothing.

\section{SUMMARY}

The province government wants to resolve the important livelihood projects. Old-Age Instustry is the best way. It can help family adults to raise their parents and bring lots of employment positions. It is an emerging industries and a win-win way. 
First, our government should research the real situation, study internal and external experience, have a long-term plan, how, where, how many people to do. The plan could well guide the new industry - caring old people and helping graduates and unemployment people do pioneering work. The plan includes everything from grants to tax credit $s$ to encourage old-age care industry.

Second, our government could open the field and introduce internal and oversea capital. Society companies can pour into the massive funds and bring market competition. Let market guide price. The price and service can satisfy old people and their family.

Third, our policy should help young people to do the emerging work, especially medical graduates who have professional advantage. Our government should give them some policy support, financial aid and tax breaks.

There are four types of institution endowment -- Senior Apartments, Retirement Home, Nursing Home and Alzheimer's Hospital. We should offer people to fit the type by their income and acceptance.

\section{ACKNOWLEDGEMENT}

This research was from the items' How to solve the bottleneck of medical graduates difficulty in finding employment and the shortage of health care workers in counties and towns' and' Study Feasibility on Community Pension in Shaanxi Province' financially supported by the Shaanxi Science and Technology Department support.

\section{REFERENCES}

[1] China statistical yearbook 2016, China Statistics Press

[2] Shaanxi Province statistical yearbook 2016, China Statistics Press

[3] How to Resolve the Problem of Old People in CHN, Dong Xiao-jing,2017,Destech Publications 